\title{
Bohm`s Quantum Potential Approach to Consciousness from the Perspective of a Four-Valued Logic
}

\author{
Marcus Schmieke* \\ *Institute of Existential Consciousness Research (ECR), Kraenzlin, Germany \\ *Dev Sanskriti University, Haridwar, India \\ https://doi.org/10.36018/dsiij.v17i.206
}

\begin{abstract}
Parallel to David Bohm's development of a realistic interpretation of quantum physics, German philosopher and logician Gotthard Günther worked on a generalization of the classical two-valued logic to satisfy the ontological requirements of quantum physics as well as of cybernetics. Both of these new disciplines introduced information and consciousness into the terminology of science. These terms and concepts need to be reflected in logic, ontology and the theory of science. David Bohm suggested an expansion of his own model by generalization and iteration of the quantum potential to include consciousness and mental states into a new psycho-physical theory. This article proposes Günther's four-valued logical system of meaning/reflection as a theoretical scientific frame for this expansion of Bohm's theory and discusses its ontological implications.
\end{abstract}

Keywords. David Bohm, Gotthard Günther, Consciousness, Quantum potential, Implicate order, Four-valued logic, Reflection, Copenhagen Interpretation, Cybernetics, Information Field

\section{Gotthard Günther's Ontological and Logical Expansion of Quantum Theory}

In his article "Cybernetic Ontology Operations" (Günther 1976) (1), German philosopher and logician Gotthard Günther describes the logical and ontological basis of quantum physics and its until now unresolved conflicts which arise due to applying two valued logical terminology to a reality of higher complexity.

The basic intention of science is to develop an objective description of reality. In terms of logic this implies a clear dichotomy between the subjective and the objective, which oppose each other as inverse components of reality. In this perspective of the classical Aristotelian logic, reality is the conjunction of these inverse components. This in turn implies that the objective world can be conceived as a self-contained entirety, as opposed to subjectivity in general. This view is consequently followed in classical physics, which therefore contains no trace of subjectivity at all. Physics idealizes the individual object whose existence is isolated from relations to other objects or expressions of subjectivity byexperience or choice. Classical physics is also absolutely governed by the law of causality, which, in turn, does not allow any influence of mind or 
consciousness beyond the purely material, objective causation.

Heisenberg stated that quantum physics "starts from the division of the world into the object and the rest of the world" (Heisenberg 1936) (2). In this so called "Heisenberg cut", the object is placed on one side, whereas the rest of the world is already a conjunction of subject and object, as it contains the rest of the world as an "object as a subject" and the "subject as a subject".

\begin{tabular}{|l|l|}
\hline $\begin{array}{l}\text { Objective Object } \\
\mathrm{O}^{\circ}\end{array}$ & $\begin{array}{l}\text { Subjective Object } \mathrm{O}^{\mathrm{s}}<\text { subjective } \\
\text { Subject } \mathrm{S}^{\mathrm{s}}\end{array}$ \\
\hline
\end{tabular}

The objective Object $\mathrm{O}^{\circ}$ and the subjective Subject $\mathrm{S}^{\mathrm{s}}$ are the two inverse poles of the classical objectsubject dichotomy, whereas the mixed states refer to the Subject as Object $S^{0}$ or the Object as Subject $\mathrm{O}^{\mathrm{s}}$.

In order to establish the symmetry between the classical subject and object, the former logical conditions need to be complemented by a separation of the absolute subject from the rest of the world, which is a conjunction of the pure Object $\mathrm{O}^{\circ}$ and the objective Subject $\mathrm{S}^{\circ}$. Here the objective Subject $S^{0}$ is referring to the part of the objective reality that serves as a subject for the objective Object $\mathrm{O}^{\circ}$.

\begin{tabular}{|l|l|}
\hline $\begin{array}{l}\text { Objective Object } \mathrm{O}^{\circ}<\text { objective } \\
\text { Subject } \mathrm{S}^{\circ}\end{array}$ & $\begin{array}{l}\text { Subjective Subject } \\
\mathrm{S}^{\mathrm{s}}\end{array}$ \\
\hline
\end{tabular}

Quantum physics in Heisenberg's interpretation obviously maintains a two-valued classical logical calculus, so it cannot assign different logical values to the four different states $\mathrm{S}^{\mathrm{S}}, \mathrm{O}^{\mathrm{S}}, \mathrm{O}^{\mathrm{O}}$ and $\mathrm{O}^{\mathrm{S}}$ described here (Günther 1954) (3); the reason being that the Copenhagen Interpretation of quantum physics is based on the fact that any experiment needs to be described from its onset by using the two-valued logical terms of classical physics. There is no alternative to this kind of thinking, because empirical consciousness requires a two-valued structure when it is touching objective facts.

Therefor Gotthard Günther states (Günther 1976) (4): "It may be said that the concept of Being or of Reality developed on the platform of two-valued logic is entirely irreflexive. This is why Schrödinger`s complaint that it is impossible to discover subjectivity and subjects in our present scientific world-conception is more than justified." For the same reason, information does not have a logical place or value within two-valued logic, as it can only contain one positive value and that is being. Information about being is already another level of reflection, as is the meaning of information.

In a two-valued logical system, one of the two values needs to be designated, whereas the other one remains wholly unknown or negative. If we decideon the object, a theory will know everything about the object, whereas the subject remains a mysterious soul that knows the object in objective terms. If the designation favors the subject like in the German Idealism of Fichte and Hegel, the resulting philosophy knows everything about the transcendental subject, whereas the genuine object, the thing itself, remains unknown and finally disappears. Physics as an objective description of reality necessarily chooses the object as the designated value, so that the subject remains unknown.

The theoretical consciousness of the modern scientific period that started in the beginning of the twentieth century began for the first time to deal with the subject and the subjective within science and started to empirically collect facts from those levels of reality that did not fall into the scope of 
the then prevalent two-valued consciousness. In a purely classical ontology, the subject and subjective can never be present within the objective description of the objective. More-valued logical thinking and a richer ontology are required to distinguish among the levels of distributed subjectivity and more than one ontological level of reality. The problems of the Copenhagen Interpretation arising from this dilemma have been appearing since almost 100 years as serious paradox and remained unsolved through Nils Bohr's mystical concept of complementarity. Itmay be some interesting background information that Nils Bohr borrowed the term “complementarity” from William James' psychological language (Stephenson 1986) (5), where it was already a term for distributed subjectivity.

\section{David Bohm`s Quantum Potential and Its Generalization Towards Consciousness and Meaning}

David Bohm developed an equivalent mathematical and physical formalism to restore classical logic by creating a classical object within quantum theory, which within itself contains the cut between the isolated object as particles (the explicate order) and the guiding wave (the implicate order). It assigns clear classical trajectories to each particle, as precise as the position of the particle and its momentum are known, with Heisenberg's uncertainty principle remaining valid (Bohm 1952) (6). In this model, both the guiding wavefunction (implicate order) and the particles (explicate order) have an objective ontological status. All the nonlocal and acausal properties of quantum theory are encoded in the wavefunction of the implicate order that guides the particles through space and time, enfolding the explicate order. Maintaining the clear object/subject dichotomy of classical logic, Bohmian quantum mechanics is a good candidate for developing a model of reality that includes states of minds and physical correlates of consciousness as well as contents of consciousness in a consistent and logical manner (Pylkkänen 2017) (7) by being expanded towards a higher logical complexity.

The basis for this Bohmian expansion of quantum mechanics is the very process by which Bohm extracts the implicate order from the traditional wavefunction of quantum theory. It corresponds to the quantumpotential which is formed from its second spatial derivation. The second spatial derivative of a particle'strajectory refers to its form rather than to its motion. As stated byPylkkänen (8):

"However, in his later development of the theory, Bohm realized that there is something very strange and radical in the way the wave affects the particle according to the mathematical description. The quantum wave or field is not pushing and pulling the particle mechanically as a classical field would. Instead, it is only the form of the field that matters (mathematically, the field gives rise to a potential, but this depends only on the 2nd spatial derivative (= form, shape) of thefield, not on the amplitude (= size) of the field). Bohm suggested that the shape of the quantum field carries information about the environment of the particle and is literally INFORMING or putting this form into the energy of the particle. This is information for the electron, not information for us - we are thus using the notion of information in a more objective sense than is usual.”

Therefor the quantum potential can be considered as a field that shapes the particles passing through space. Its nature can be seen as information rather than as another physical field, and as such it is subject to a different set of rules. To distinguish the informational character of the quantum potential from purely mathematical information, 
Bohm termed it "active information", as it influences and informs the development of a physical state. Just as Gotthard Günther was showing that a theory including matter, information and mind needs at least three logical values, here as well we recognize the need for a multi-valued logical theory.

The activity of information is defined by Bohm as its meaning. Information is active information if it is recognized at the location of its effect as meaning.

As stated by Pylkkänen (9):

"The suggestion that the principle of active information applies all the way from the quantum level to the level of human subjective experience opens up a new way of thinking about the relationship of mind and matter, which Bohm sketched in a number of articles (e.g. Bohm 1989 (10), 1990 (11)). He drew attention to the hierarchical structure of the mind, in the sense that given that we are in a certain mental state, it is always possible to become aware of that state from a higher level of mental activity. Once the higher order activity apprehends the meaning of the lower-order state, there is a possibility that a yet higher-order activity emerges, which organizes the lower-order information into agreater whole.

In terms of the implicate order one could say that the different levels enfold and unfold each other.

A higher level enfolds information about the lower ones; and once the meaning of this information at the higher level is apprehended, this meaning unfolds into lower levels, which shows itself in the way the lower-level information gets organized. Or, as Bohm would put it, meaning is the activity of information.”
Information by its very nature is a nonlocal entity,acting locally if its meaning is decoded in certain areas of space and time. In its capacity as active information it acts physically by informing the development of physical states without having physical properties itself, such as position and time. This is especially important for the integration of Bohmian quantum theory with the theories of relativity.

The Bohmian quantum potential as active information creates the nonlocal effects of quantum interconnectedness on the physical level and the higher level of unity which is observed in quantum objects and encodes the properties of the environment of the described physical objects in terms of the experimental setup, the observed physical properties of the object and other important features of the objects' environment like e.g. the presence of slits, features such as magnetic flux lines and differences in gravitational potential.

The probabilistic effects of the Copenhagen Interpretation are reflected in Bohmian quantum mechanics by the inability to simultaneously determine the exact position and momentum of a particle. Which exact trajectory the particle will take in a given experiment or in between two events of observation depends on the exact values of these physical properties. The exact measurement of one of these properties immediately updates the trajectories of the particles in the whole universe. But what is the ontological status of the active information of the quantum potential?

\section{Bohm`s Repeated Formation of the QuantumPotential as Günther's Iterated Double Reflection}

According to Gotthard Günther's ontological and logical considerations on information it is neither physical (objective) nor mental (subjective) by 
nature, but occupies a third ontological value. Information is neither physical nor mental; it possesses both qualities, it occupies a logical location beyond the subject-object dualism (Günther 1979) (12). Günther also remarks that the current two-valued theory cannot distinguish between information and its meaning. Additionally, the receiver and the transmitter of information need to be identified as an "it", as a two-valued logical system cannot distinguish between "I" and "you". Handling information and communication along with the difference between the $1^{\text {st }}, 2^{\text {nd }}$ and $3^{\text {rd }}$ person, information and meaning will in themselves require a multi-valued logical approach.

Information is a reflection on a physical or mental state and therefore of a different nature than the physical or mental state itself. Still it is not identical with the subject, which is the total negation of the physical object and therefore doesnot possess these designations itself. Reflecting again on the active information reveals its meaning on a level of higher connectedness. Bohm considered this process of reflection by the quantum potential to be reproducible (Bohm 1990) (13).

“... one could begin by supposing, for example, that as the quantum potential constitutes active information that can give form to the movements of the particles, so there is a superquantum potential that can give form to the unfoldment and development of this first order quantum potential. This latter would no longer satisfy the laws of the current quantum theory, which latter would then be an approximation, working only when the action of the superquantum potential can be neglected. Of course, there is no reason to stop here. One could go on to suppose a series of orders of super-quantum potentials, with each order constituting information that gives form to the activity of the next lower order (which is less subtle)”.

With each iteration the wholeness and integrity of the meaning of information is increased, and a higher level of being is achieved which next to a higher degree of quantum wholeness might also reflect mental qualities along with their physical correlates of consciousness. In this way, Bohm considered the iterative construction of the quantum potential to be a way to include subjectivity and subjects into the formalism. In this process, the higher levels of iteration of the quantum potential donot have to strictly follow the laws of quantum physics, as proposed e.g. by the Generalized Quantum Theory of Walach, Römer and Atmanspacher (Walach et al. 2020) (14). By this reflective process of iterative formation of the quantum potential a more and more dense and holistic realm of meaning, mental contents and empirical consciousness might be created, which, similar to active information, doesnot fit into the classical object-subject duality. It creates ontological levels of distributed subjectivity and requires additional logical and ontological depth and width.

Gotthard Günther suggested for this purpose that a higher dimensional logic of reflection and meaning needs to be formalized, one that recognizes the reflective nature of reality and is rich enough to contain being, the process of reflection, information, meaning, mental states, physical correlates of consciousness, introspection and the pure subjectivity of consciousness. Following Hegel's process of the second or double reflection, Günther established a four-valued logical system, based on material being, the first reflection of its meaning and the second reflection, creating the double reflection in itself of the reflection in itself and in others (Günther und Hegel; in Maluschke 1964) (15) as the basis of empirical self- 
consciousness. Hegel already recognized that the second reflection can be repeated in an unlimited way, without ever reaching a limit of completion. It corresponds to discovering higher and higher levels of meaning and consciousness invested into being. Bohm recognized this process to be a potential expansion of his implicate order by iteration of the construction of the quantum potential to include meaning and mind into the picture. It was Gotthard Günther who recognized the incompleteness of this "bad infinity", as Hegel called it, by the introduction of a third reflection as a total negation of the potential of the unlimited iteration of the second (double) reflection. It thus completes the logical circle by the complete reflection of a limit of wholeness with an unlimited width of reflection into a pure subject. Reflecting the unlimited width of the wholeness of being, the subject of this final reflection possesses an unlimited depth of reflection as a transcendental introspection. Here David Bohm's and Gotthard Günther's visions meet by creating the ontological, logical and formal scientific frame for an expansion of quantum physics which solves the contradictions and paradoxes of the Copenhagen Interpretation. As by its very nature the Bohmian formalism of the quantum potential is strictly causal, it doesnot allow any subjectivity within the first level of its application. Only the iteration on the first level of information creates meaning and its corresponding mental states, the latter not having to strictly follow the laws of quantum physics anymore and therefore allowing for consciousness itself to create active information. The irreflective momentum of this logic is the holomovement between the first level implicate order and the explicate order of physical objects like particles. In itself this level is not irreflective but an ongoing reflective process enfolding the implicate order. This level for itself has no subjective nature. Therefor it serves as the objective momentum of the first reflection.
Here we see the parallel structures of Bohm's expansion of quantum mechanics and Günther's expansion of the Aristotelian logic to a four-valued logical system with an ontology including being, information, mind and consciousness within one single system. According to Bohm, in each iterative step a higher reflection needs to remain unconscious to reflect on the lower levels of conscious meaning.

The principle of the quantum potential as information for an electron or any other physical object described by the theory can be generalized as information for a conscious being as in this statement by Rosenthal 1997 (16):

“...our thoughts may contain a whole range of information content of different kinds. This may in turn be surveyed by a higher level of mental activity, as if it were a material object at which one were 'looking'."

In his comment to this quote Pylkkänen states that a higher level reflection on some information or mental content (surveying, looking) makes the lower-order information content conscious. $\mathrm{He}$ continues (Pylkkänen2016) (17):

"But it also seems that Bohm does not explain why there is consciousness present in such surveying. Rather it seems that he just presupposes that we can be conscious of the information content of a given level of thought, in the same way that we can be conscious of the material objects when we look at them. He further notes that we can also become aware of the surveying itself, in a yet higher-order mental activity of surveying. So perhaps becoming conscious of a given content or activity requires that one take a "higher-order step", so that the content or activity in question becomes the object or target of surveying or mental looking. In summary, it seems that consciousness in the Bohmianscheme typically involves a higher-order structure, but we 
are not given an explanation of the origin of consciousness itself.”

A final reflection on the whole process of iterative reflections leads to the complete wholeness of consciousness, as Gotthard Günther states in Formal Logic, Totality and the Super-Additive Principle: "The logical prototype of all totalities (Ganzheiten) is the system of consciousness." At this level, the final total reflection opposes the totality of the system of consciousness in a twovalued logical way (Günther 1976) (18).

Pylkkänen relates this process to the causation of consciousness (19):

"So, how might we use higher order theories of consciousness to explain consciousness more fully in the Bohmian scheme? A simple possibility would be to postulate that what makes a given mental state (or level of information or mental activity in Bohmian terms) conscious is that there exists a higher level of unconscious information, which has the content that one is the first order mental state or activity. But why would the existence of such higher-order information make the first order mental state conscious? The postulate itself is indeed merely a postulate - it does not explain or make intelligible why the higher order information is able to make the first order information conscious. (For an attempt to apply higher order theory of consciousness in the context of the Penrose-Hameroff approach, see Hameroff, Gennaro and Pylkkänen 2014 (20)).”

From Günther's perspective it is not necessary to explain why consciousness appears, as it is the natural second ontological theme (the first theme: being, the second theme: reflection) in a fourvalued logical system: It is itself the final reflection. The final $3^{\text {rd }}$ reflection accounts for the wholeness of self-consciousness and its transcendental nature.
The nature of each finite level of the iteration of the $2^{\text {nd }}$ reflection is information, with activity as its meaning. The meaning of this entirety of information is reflected on by the final $3^{\text {rd }}$ reflection. In this way, the highest achieved wholeness of information becomes the content of consciousness.

\section{Four-Valued Logic as a Scientific Theory Frame of the Psycho-Physical Expansion of Bohm's Quantum Theory}

Gotthard Günther considered four-valued logic to represent the ontological and logical status of the theoretical scientific theories of his time (Günther 1991) (21). He was mainly referring to the development of quantumtheory and cybernetics. Quantumtheory, particularly in its most prominent version of the Copenhagen Interpretation, considers knowledge about reality to be more fundamental than physical reality itself and opens the ontology of physics towards the concept of consciousness. Information becomes one of the most basic levels of reality. Cybernetics elevated information and the processing of information to a new ontological status. The reflection of information processing on information in particular is the main focus of cybernetics. Modern versions of the quantum-cybernetic approach to cosmology and physics consider reality as a universal process of information processing, simulated on a quantum-computer, calculating its own existence (Llyod 2013) (22).

Both of those disciplines, quantumtheory and cybernetics, direct our attention towards a consistent ontological and logical model that includes consciousness, knowledge of information, information, reflection of information, meaning and consciousness as well as physical processes. Such a broad ontological model requires more than a monothematic two-valued logical system. The Copenhagen Interpretation of quantumtheory itself replaces purely objective physical reality with a 
reflection of knowledge on physical being, which allows an active or causal role of consciousness by being involved as a precondition of the collapse of the wave function. The first expansion of classical logic is a three-valued logical system. It gives thinking (as reflection) a logical place and objectifies self-consciousness as a double reflection. The price we have to pay for this is the object losing its place: It gets lost through the reflection on the reflection (Günther 1976) (23). But already in a four-valued logical system, the object is then re-discovered, because the reflection possesses place values which cannot be interpreted as subjective epistemological processes, related to the subject as "I" or "you". They need to be interpreted as objective levels of reality. Consciousness has already withdrawn itself from these levels by identifying itself with the deeper reflections.

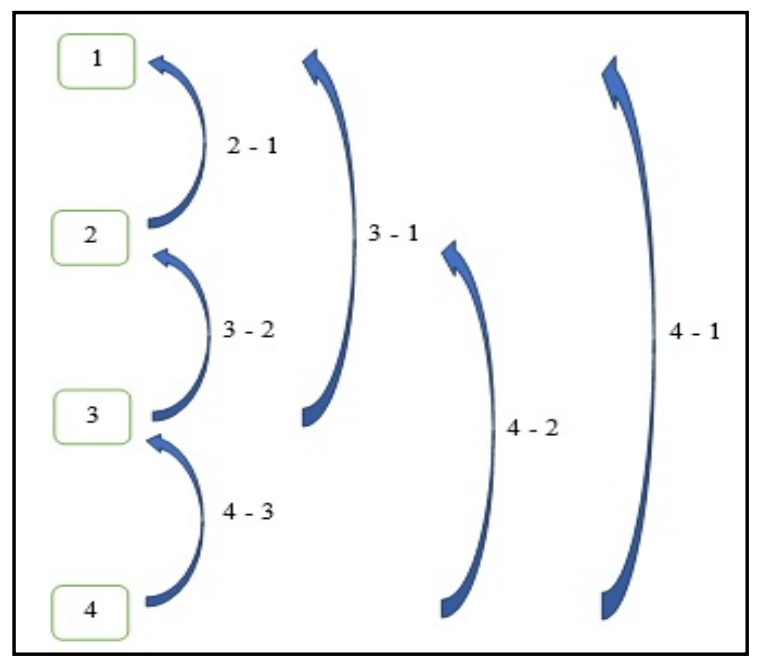

Figure 1: Six two-valued reflections as place values in a fourvalued logic

In a four-valued logical system, we find three levels of objective existence (with a reflection depth of 1) and three states of consciousness (with a depth of reflection of 2 and 3). It altogether contains six two-valued logical systems (Schmieke 2019) (24).

The deepest reflection 4-1 reflects on the object as being, which also changes its character as the depth of the reflection 3-2 increase (Günther 1976) (25). The increasing depth in the iterative 2-3 twovalued system realize a higher level of wholeness (information, meaning, mental content) in the observed object. The 4 - 1 reflection is the consciousness of oneself as a being. It possesses unlimited depth in the conscious reflection and unlimited width in the nature of the object.

\begin{tabular}{lcc}
\hline Theme of Reflection & Depth & $\begin{array}{l}\text { Two-valued } \\
\text { reflection }\end{array}$ \\
\hline Physical quantum potential & 1 & $1<->2$ \\
\hline $\begin{array}{l}\text { Information, meaning and } \\
\text { mental content }\end{array}$ & 1 & $2<->3$ \\
\hline $\begin{array}{l}\text { Wholeness of Information, } \\
\text { meaning and mental content }\end{array}$ & 1 & $3<->4$ \\
\hline $\begin{array}{l}\text { Being - width of the reflection in } \\
\text { being }\end{array}$ & 2 & $1<->3$ \\
\hline $\begin{array}{l}\text { Meaning - depth of the reflection } \\
\text { as the conscious process }\end{array}$ & 2 & $2<->4$ \\
\hline $\begin{array}{l}\text { Selfconsciousness } \\
\text { Table 1: Six two-valued logics as place values of a four-valued } \\
\text { logical system }\end{array}$
\end{tabular}

In Figure 1 the six two-valued reflections are shown as two-valued reflections between the four values of the four-valued logical system in a circular representation. Value 1 is the quantum potential guiding the particle constellations as the mutual reflection of the first level implicate and explicate order. Value 2 corresponds to a mental content, meaning or information, that is object to an iteration of reflections from value 3 , which corresponds to ever higher contents of consciousness. In this way, the wholeness of the described reality of value 1 increases with each iteration. As David Bohm considered value 2 to be of the nature of active information, the iteration between value 3 and value 2 creates more and more holistic or integrated information. It reflects the Bohmian bidirectional holomovement in a dynamic super-hierarchical structure. The activity of information is its meaning. A reflection on information makes its meaning explicit and potentially conscious. In this way, a hierarchy of 
more holistic information-meaning relations is developed. In its wholeness, it can be understood as an Information Field which connects information to its meaning towards the lower level of information and towards the higher level of consciousness. Information as active information activates the lower level on which it reflects, and at the same time manifests its meaning as content of a level of empirical self-consciousness, created by the next step of reflection.

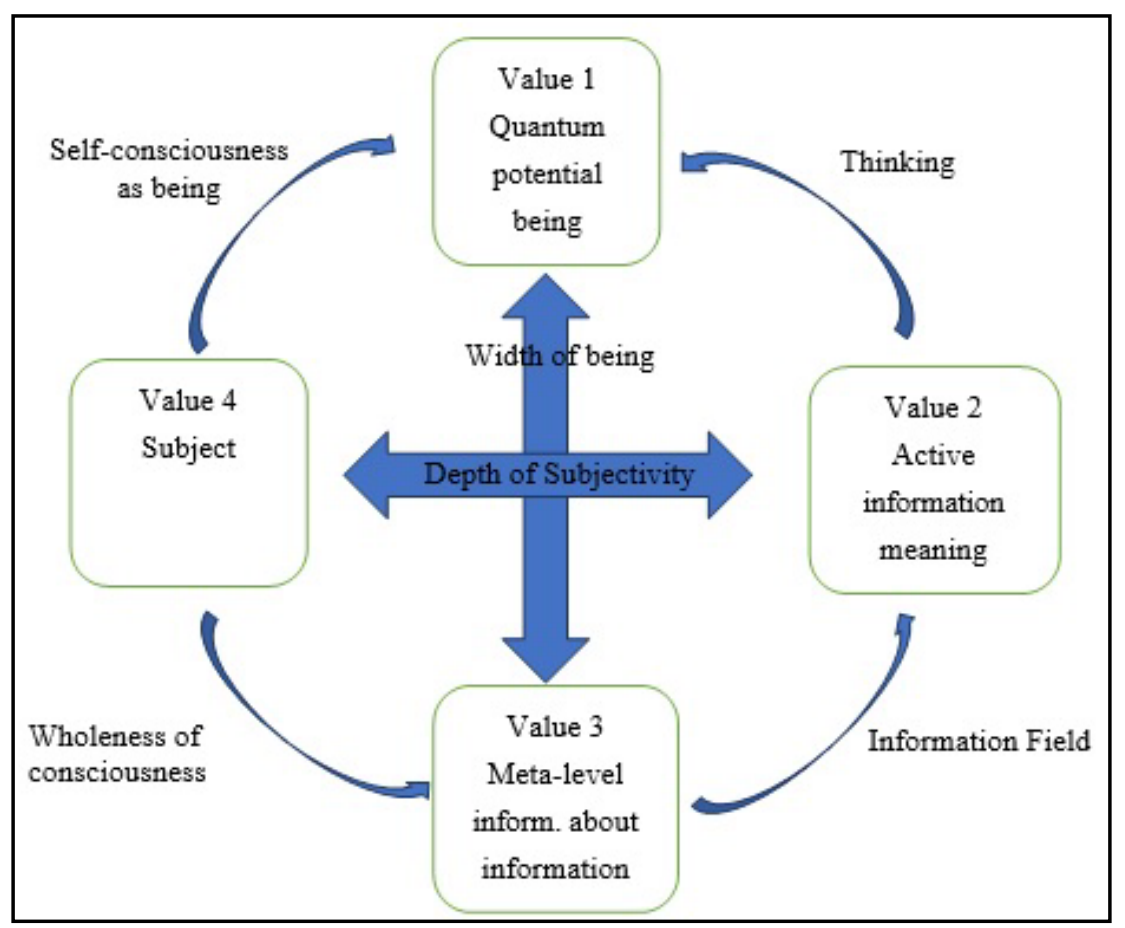

Figure 2: Four-Valued logical reflection structure

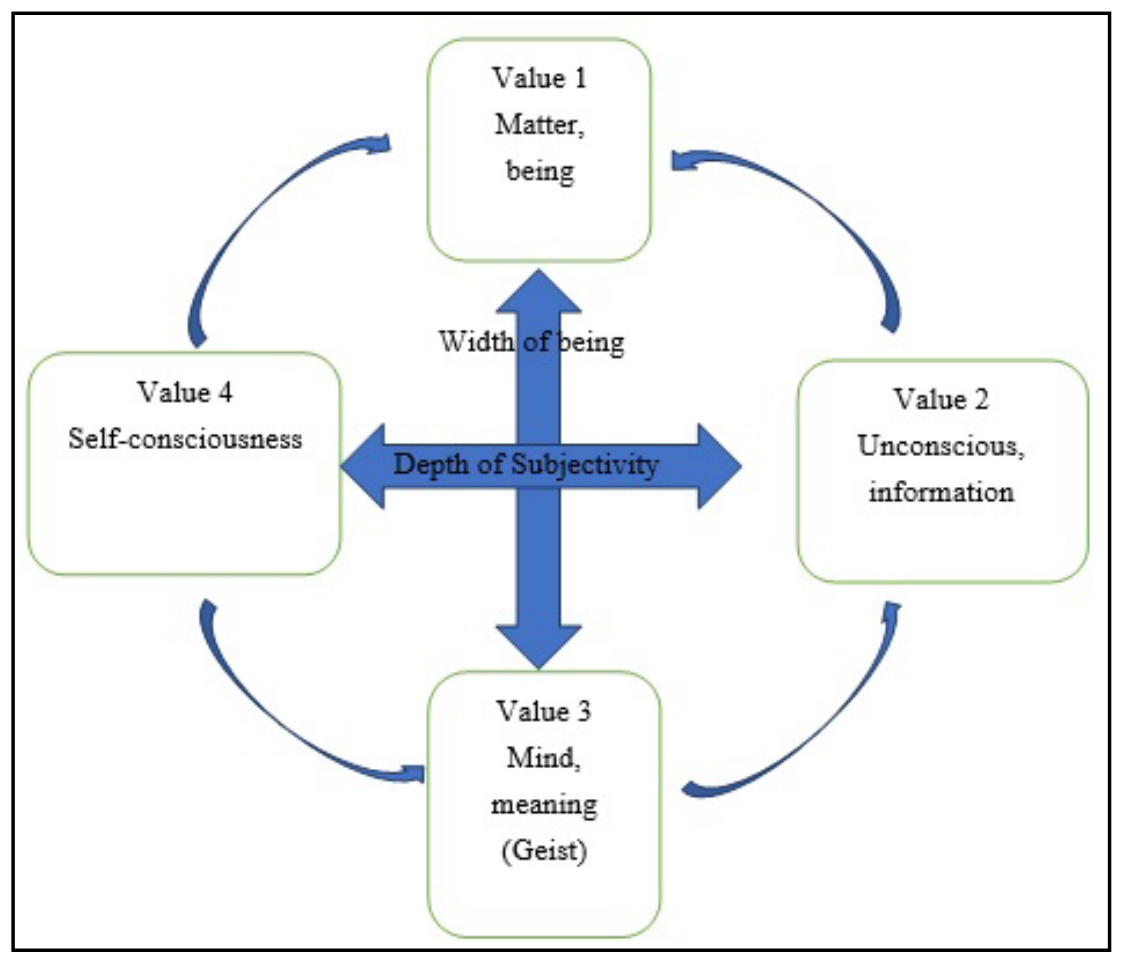

Figure 3: Orthogonal complementarity of objectivity and subjectivity 
The final reflection on the totality of reflections from value 4 results in transcendental selfconsciousness of unlimited reflective depths and final reflection on the level of being (value 1).

In this context, David Bohm and Gotthard Günther put special emphasis on a new understanding of information and the iteration of information as information about information. Pylkkänen points to the relationship or information and consciousness (Pylkkänen 2016) (26):

"'Conscious of' can here be understood to include 'having meta-level information about'. This connects with higher order theories of consciousness which assume that what makes a given mental state conscious is that there exists a higher level of (typically) unconscious mental state, which has the content that one is in the first order mental state or activity (Rosenthal 1997) (27). Thus, consciousness is not assumed to be a neural or computational property, but rather something that arises when initially non-conscious mental states are related in a suitable way. It seems quite natural to think about such meta-mentality in terms of information. We could say that metamentality involves higher-order "information about information" rather than just first-order "information about the environment". In these terms, higher-order theories of consciousness suggest that consciousness essentially involves information about information. A simple possibility would be to postulate that what makes a given informational state conscious is that there exists a higher level of (typically) unconscious information, which has the content that one is in the first order informational state.”

\section{Orthogonal Complementarity}

The total reflection 4-1 refers to the existence of self-consciousness, comprehending the two reflections 3-1 and 4-2, which establish the unlimited width of being and depth of consciousness. These two infinities comprehend the complementarities of being (matter-mind (Geist)) and of consciousness (conscious and unconscious). Both of them appear to be complementary to each other, forming a double or orthogonal complementarity (Schmieke 2019) (28).

\section{Inversion of Self-Consciousness and Second Quantization of the Quantum Potential}

The $3^{\text {rd }}$ level of reflection, according to the definition of reflection, is the absolute relationship of the Self to itself. It can't become the object of another $4^{\text {th }}$ level of reflection, as it is the total reflection of reflection itself. Therefor the inversion of the $3^{\text {rd }}$ level of reflection is totally different by nature. Whereas the reflections of the $2^{\text {nd }}$ level are all still partial reflections of a limited degree of wholeness, the $3^{\text {rd }}$ level reflects wholeness into itself.

Here the subjective reflection is the subject of inversion. By inversion it loses its subjectivity and becomes objectivity or being. This inversion of the Self as $I$ is the You as objective subjectivity $S^{0}$. The You is a definite object for the world (explicate order), but internally the infinity of reflection (the ultimate implicate order). The transfinite power of the unique I is inverted into the ultrafinite power of the You. The infinite reflection of the I-self is a countable infinity, whereas the totality of potential Yous is a set, containing unlimited transfinite sets. The unlimited places of the You (explicate order) are created and annihilated from the implicate field of I-ness. The inversion of the $3^{\text {rd }}$ reflection appears to be analogous to the second quantization of the quantum potential (Jamali et al. 2019) (29). It allows the creation and annihilation of the objective Self-consciousness (You) from the perspective of the I-consciousness. From the Iperspective of the $3^{\text {rd }}$ reflection, annihilation seems unthinkable (Bhagavad Gita 2.20) (30). 


\section{Conclusion}

The purpose of this article is to elaborate the parallels of Gotthard Günther's philosophicallogical and David Bohm's psycho-physical approaches to solve the post quantumtheory situation of contradictory paradoxes and the ontological dissatisfaction of a majority of physicists with the epistemic Copenhagen Interpretation. Bohm introduced the idea of quantum potential to save the realistic ontological status of matter within physics and expanded it by the trans-physical iteration of the quantum potential towards mental states and psychophysical states of more comprehensive wholeness. The quantum potential already introduces a reflective nature within the physical level itself. Gotthard Günther points to Hegel's bad infinity of the iteration of the second reflection towards ever newer levels of empirical self-consciousness and completes it by a final third reflection on the totality of the iteration of reflection, thus establishing the ontological state of the total wholeness of self-consciousness and its transcendental nature. The thusly achieved fourvalued logic provides a fitting ontological and reflective richness as a frame for post-quantum scientific theories. Bohm's and Günther's systems show strong parallel features and structures, with a close relation of Bohm's generalized quantum potential towards Hegel's double reflection and their intrinsic potential for unlimited iteration. Günther's analysis of six place values provides an ontological basis for Bohm`s psycho-physical model.

\section{References}

1. Gotthard Günther, Beiträge zur Grundlegung einer operationsfähigen Dialektik, Erster Band, CyberneticOntologyOperations, Felix Meiner Verlag 1976.

2. Heisenberg, W. "Prinzipielle Fragen der modernen Physik". In Neuere Fortschritte in den exakten Wissenschaften. Fünf Wiener Vorträge, fünfter Zyklus, 1936;91-102. Leipzig: Franz Deuticke.
3. Gotthard Günther: Dreiwertige Logik und die Heisenbergsche Unbestimmtheitsrelation, in: Actes du IIèmeCongrès Internationale de l'Union Internationale de Philosophie des Sciences, Zürich 1954, Vol. II, p. 53-59.

4. Gotthard Günther, Beiträge zur Grundlegung einer operationsfähigen Dialektik, Erster Band, CyberneticOntologyOperations, p. 315, Felix Meiner Verlag 1976.

5. William Stephenson, William James, Niels Bohr, and Complementarity: I-Concepts, The Psychological Record, 1986, volume 36, pages519-527.

https://doi.org/10.1007/BF03394970

6. Bohm, D., A Suggested Interpretation of the Quantum Theory in Terms of "Hidden Variables" I and II, Phys. Rev., 1952;85(2): 166-179 and 180-193.

https://doi.org/10.1103/PhysRev.85.180

7. Paavo Pylkkänen, Is there Room in Quantum Ontology for a Genuine Causal Role for Consciousness?,The Palgrave Handbook of Quantum Models in Social Science pp 293-317; Springer 2017. https://doi.org/10.1057/978-1-137-49276-0_14

8. Paavo Pylkkanen, Quantum Theory, Active Information and the Mind-Matter Problem, Contextuality from Quantum Physics to Psychology (pp.325-334), 2016. https://doi.org/10.1142/9789814730617_0014

9. Paavo Pylkkanen, Quantum Theory, Active Information and the Mind-Matter Problem, Contextuality from Quantum Physics to Psychology (pp.325-334), 2016 https://doi.org/10.1142/9789814730617_0014

10. David Bohm, Meaning and Information. In P.Pylkkänen ed. The Search for Meaning. Wellingborough: Crucible, 1989.

11. David Bohm. A new theory of the relationship of mind and matter. Philosophical Psychology, 1990, 3, 271-286.

12. Gotthard Günther, Beiträge zur Grundlegung einer operationsfähigen Dialektik, Zweiter Band, Information, Communication and manyvaluedlogic, p. 134-148, Felix Meiner Verlag 1979. https://doi.org/10.28937/978-3-78732555-9

13. Bohm, D. A new theory of the relationship of mind and matter. Philosophical Psychology, 1990;3:271-286. https://doi.org/10.1080/09515089008573004 
14. Atmanspacher $\mathrm{H}$, Römer $\mathrm{H}$, Walach $\mathrm{H}$. Weak quantum theory: Complementarity and entanglement in physics and beyond. Foundations of Physics 2002;3:379-406.

https://doi.org/10.1023/A:1014809312397

15. Günther Maluschke; Reflexion und Dialektik im Zeitalter der Kybernetik, Soziale Welt, 18. Jahrg., H. 4 (1967:pp. 289308.

16. Rosenthal, D. M.. A theory of consciousness. In The Nature of Consciousness; N. Block, O. Flanagan, G. Guüzeldere, Eds.; MIT Press: Cambridge, MA, 1997.

17. Paavo Pylkkanen, Quantum Theory, Active Information and the Mind-Matter Problem, Contextuality from Quantum Physics to Psychology, 2016:pp.325-334. https://doi.org/10.1142/9789814730617_0014

18. Gotthard Günther, Beiträge zur Grundlegung einer operationsfähigen Dialektik, Erster Band, Formal Logic, Totality and the Super-Additive Principle, p. 349, Felix Meiner Verlag 1976.

19. Paavo Pylkkanen, Quantum Theory, Active Information and the Mind-Matter Problem, Contextuality from Quantum Physics to Psychology (pp.325-334), 2016. https://doi.org/10.1142/9789814730617_0014

20. Hameroff, S., Gennaro, R. and Pylkkänen, P. HOT to DOT: A 'Deeper-Order Thought' Theory of Consciousness. In Brain, Mind and Cosmos, Trident, 2014.

21. Gotthard Günther, Metaphysik, Die aristotelische Logik des Seins, Beiträge zur Grundlegung einer operationsfähigen Dialektik, Band 1, p. 187, Felix Meiner Verlag, Hamburg 1991.
22. Seth Lloyd, The universe as quantum computer. In: H. Zenil (Hrsg.): A Computable Universe: Understanding and exploring Nature as computation.World Scientific, 2013 https://doi.org/10.1142/9789814374309_0029

23. Gotthard Günther, Beiträge zur Grundlegung einer operationsfähigen Dialektik, Erster Band, Die aristotelische Logik des Seins, p. 187, Felix Meiner Verlag 1976.

24. Marcus Schmieke, The depth of reflection of consciousness in orthogonal complementarity, unpublished 2019.

25. Gotthard Günther, Beiträge zur Grundlegung einer operationsfähigen Dialektik, Erster Band, Die aristotelische Logik des Seins, p. 185, Felix Meiner Verlag 1976.

26. Paavo Pylkkanen, Quantum Theory, Active Information and the Mind-Matter Problem, Contextuality from Quantum Physics to Psychology (pp.325-334), 2016. https://doi.org/10.1142/9789814730617_0014

27. Rosenthal, D. M., (1997) A theory of consciousness. In The Nature of Consciousness; N. Block, O. Flanagan, G. Guüzeldere, Eds.; MIT Press: Cambridge, MA.

28. Marcus Schmieke, Orthogonal Complementarity, Tattva Viveka 2019, www.acadedemia.edu.

29. Mohammad Jamali, Mehdi Golshani, Yousef Jamali, Modified Bohmian quantum potential due to the second quantization of Schrödinger equation, Heliyon, 2019.

30. Bhagavad Gita, chapter 2, verse 20. 